\title{
Editors' Commentary
}

\author{
Henry Buchwald • Nicola Scopinaro
}

Published online: 20 October 2010

(C) Springer Science+Business Media, LLC 2010

The Santoro III operation is performed by laparoscopy (five ports) plus an additional $6-\mathrm{cm}$ open incision. The procedure consists of a subtotal, 75-80\%, sleeve gastrectomy, an omentectomy, and a jejunectomy, retaining $120 \mathrm{~cm}$ of duodenum and jejunum in their normal configuration anastomosed $80 \mathrm{~cm}$ from the ileocecal valve to a $180-\mathrm{cm}$ long Roux limb. The resected stomach is gone, as is a large segment of intestine now unavailable for functional restoration of bowel continuity in case of malnutrition or a future emergency involving bowel loss. In the experience of one of the editors (NS), who has measured more than 3,000 small bowels, the mean total intestinal length is about $800 \mathrm{~cm}$; the Santoro III operation entails the excision of more than $60 \%$ of the small intestine. Of the standard metabolic/bariatric operations, only biliopancreatic diversion with or without duodenal switch and sleeve gastrectomy involve organ resections, and these resections are limited to a two-thirds distal gastrectomy or a subtotal greater curvature gastric resection. Though there is some evidence that an omentectomy might mitigate the metabolic syndrome [1], there are no definitive data to indicate that removal of the greater omentum, the "infection watch dog of the abdominal cavity," promotes weight loss.

The predecessor to the Santoro III procedure was first described in 2003 [2]. The group of Santoro, Velhote, and

\section{H. Buchwald $(\bowtie)$}

Department of Surgery and Biomedical Engineering,

University of Minnesota,

Minneapolis, MN, USA

e-mail: buchw001@umn.edu

\section{N. Scopinaro}

Department of Surgery,

University of Genoa,

Genoa, Italy associates subsequently experimented with different bowel lengths and anastomoses [3]. Their adult patients series grew and by 2008, included 600 patients [4]. During this time span of the past 7 years, the Santoro procedures have not found general acceptance in the metabolic/bariatric surgical community. Indeed, they have been criticized in the pages of Obesity Surgery by a Brazilian metabolic/ bariatric surgeon from Sao Paulo, the same city as the protagonists of this approach [5].

This paper by Velhote and Damiani represents the first report of the current Santoro procedure, the Santoro III, in a pediatric population of ten patients, with the youngest member 14 years of age. Because of the irreversibility of the intestinal resection and omentectomy of the Santoro III procedure, the Editors-in-Chief express concern and stress extreme caution in its adaptation, in particular, in adolescents. We have, therefore, invited Dr. Thomas Inge, Surgical Director of the Surgical Weight Loss Program for Teens at the Cincinnati Children's Hospital and Associate Professor of Surgery and Pediatrics at the University of Cincinnati, and his associates, to write a commentary on the Velhote and Damiani paper.

Conflict of Interest The authors declare that they have no conflict of interest.

\section{References}

1. Thörne A, Lönnqvist F, Apelman J, et al. A pilot study of long-term effects of a novel obesity treatment: omentectomy in connection with adjustable gastric banding. Int J Obes Relat Metab Disord. 2002;26:193-9.

2. Santoro S, Velhote MCP, Malzoni CE, et al. Digestive adaptation: a new surgical proposal to treat obesity based in physiology and evolution. 
Einstein. 2003;1(2):99-104. http://www.einstein.br/biblioteca/artigos/ digestiveadaptationorigina.pdf.

3. Santoro S, Velhote MC, Malzoni CE, et al. Preliminary results from digestive adaptation: a new surgical proposal for treating obesity, based on physiology and evolution. São Paulo Med J. 2006;124:192-7.
4. Velhote MC, Damiani D. Bariatric surgery in adolescents: preliminary 1-year results with a novel technique (Santoro III). Obes Surg, online, doi: 10.1007/s11695-008-9520-0.

5. Garrido Jr AB. Surgical repair of maladapted human GI tract? Discussion of the proposal for evolutionary surgery. Obes Surg. 2006;16:1380-2. 